\title{
Mass Transfer Coefficient Studies in Bubble Column Reactor
}

\author{
D.Devakumar (Corresponding author) \\ Assistant Professor, Department of Mechanical Engineering \\ Excel College of Engineering and Technology, Komarapalayam \\ Namakkal - 638183, Tamilnadu, India \\ E-mail: devakumarand@yahoo.com
}

Dr.K.Saravanan

Professor and Head, Department of Chemical Engineering

Kongu Engineering College, Perundurai, Erode - 638052, Tamilnadu, India

E-mail: rumisivaesh@yahoo.com

\author{
Dr.T.Kannadasan \\ Director - Research, Anna University- Coimbatore \\ Coimbatore-641047, Tamilnadu, India \\ E-mail: tkannadasan56@yahoo.com
}

B.Meenakshipriya

Senior Lecturer, Department of Mechatronics Engineering

Kongu Engineering College, Perundurai, Erode - 638052, Tamilnadu, India

E-mail: b.meenakshipriya@gmail.com

\begin{abstract}
Stirred bubble column are widely used in chemical and allied processes industries. Stirred bubble column reactor promotes significant liquid hold-up and long liquid residence time. It is used when a large mass transfer area and high mass transfer coefficient in both phases are desired. These columns can operate continuously with a concurrent and counter current phase flow where high interfacial areas between phases are possible with low investment cost. An experimental work was undertaken to focus the effect of various parameters like Height to Diameter ratio $(\mathrm{H} / \mathrm{D})$, Gas flow rate and Speed of the stirrer $(\mathrm{N})$ on mass transfer coefficient in stirred bubble column reactor. For this purpose, experiments were conducted in $0.14 \mathrm{~m}$ i.d column having $2 \mathrm{~m}$ height. The column with ring sparger having $67 \%$ active area is used as sparger for dispersing the dispersed phase into the continuous phase. For the optimized sparger plate, the effect of various parameters on mass transfer coefficient was studied based on $\mathrm{CO}_{2}$-absorption Technique.
\end{abstract}

Keywords: Stirred bubble column reactor, Mass transfer coefficient, Sparged column

\section{Introduction}

Bubble columns are widely used in the chemical industry, where heterogeneous gas -liquid (or) gas- solid reaction take place, particularly in which the liquid phase controls mass transfer process due to relative insolubility of gases (Lye et al., 2001). Important applications of bubble column include oxidation, hydrogenation, ozonelysis, alkyation, column floatation and waste water treatment (Yang et al., 2001). To design a bubble column as a reactor, Studies like fractional holdup, mixing time and mass transfer characteristics are needed (Ali Abdul R. N. Jasim, 2009). Many works on bubble column for holdup, mixing time and mass transfer characteristics have been reported in the literature (Shah et al., 1982; Pandit and Joshi, 1984; Thorat et al., 2004; Mashelkar, 1970; Deckwer et al., 1974; Urza and Jackson, 1975; Burekhart and Deckwer, 1976; Maclean et al., 1977; Schugerl et al., 1977; Shiaya and Duna, 1978; Alvarez - cunca at al., 1980; Mangertz and Pilhofer, 1981; Koide et al., 1984; Haque et al., 1987, Ozturk et al., 1987; Akita and Yoshida, 1973; Kawase and Moo-young, 1987; Hikita et al., 1981; Kang et al., 1999; Schumpe and Grund, 1986). The efficiency of mixing in bubble column can be enhanced by employing stirrer in the conventional bubble column. The only work reported in the literature stirred bubble column is by 
(Shanmugam et al., 2008). Knowing the importance of mass transfer characteristics in the design of stirred bubble Column, the present work focus on the determination of mass transfer characteristics in the stirred bubble column.

\section{Experimental set up and methods}

Mass transfer experiments were carried out using the experimental setup as shown in Figure 1 . It consists of $0.14 \mathrm{~m}$ i.d in diameter and $2 \mathrm{~m}$ in height. In order to visualize the flow, the column is made up of transparent perpax (Acrylic). The compressed air from the compressor is sparged in to the bubble column through sparger. The sparger plate is made up of acrylic having an active area of $67 \%$. The design details pertaining to sparger is shown in Table 1 and details of column is shown in Table 2. Mass transfer coefficient was determined based on the Denckwards methods. The gas flow rate was measured using recalibrated rotameter.

\section{Results and discussions}

\subsection{Effect of mass transfer coefficient on $H / D$ ratio}

The effect of mass transfer coefficient was studied for stirred bubble column. Since the H/D ratio is also one of the vital parameter which influence the mass transfer characteristics, a systematic work was undertaken to vary the H/D ratio from 2 to 5 . The graph was drawn between H/D ratio and mass transfer coefficient $\left(K_{L}\right.$ a) is shown in Figure 2. From this figure, it can be seen that mass transfer coefficient increases with decrease in H/D ratio. As a mass transfer characteristic depends on phase holdup, hence increase in holdup shows high mass transfer coefficient.

\subsection{Effect of mass transfer coefficient on speed of the stirrer}

Speed of the stirrer was varied in the range of $50 \mathrm{rpm}$ to $200 \mathrm{rpm}$. The speed of the stirrer was found to affect the mass transfer coefficient marginally. The stirrer plays a vital role in breaking of large bubbles into smaller ones. The effect of speed of the stirrer on mass transfer coefficient $\left(K_{L} a\right)$ is shown in Figure 3. From the figure, it could be seen that, with the increase in the speed of the stirrer, the mass transfer coefficient increases. This may be due to the breakage of the larger bubbles into smaller ones; hence the contact area available for mass transfer between the two phases increases.

\subsection{Effect of mass transfer coefficient on superficial gas velocity}

The effect of gas flow rate on mass transfer coefficient for constant H/D ratio is shown in the Figure 4. From the figure, it can be seen that mass transfer coefficient $\left(\mathrm{K}_{\mathrm{L}} \mathrm{a}\right)$ increases with increase in superficial gas velocity $\left(\mathrm{V}_{\mathrm{G}}\right)$. More and more gas bubbles occupy the column as the superficial gas velocity increase. Thus column shows more $\mathrm{K}_{\mathrm{L}}$ a for higher $\mathrm{V}_{\mathrm{G}}$.

\section{Comparison of mass transfer coefficient in bubble column with and without stirrer 4.1 Comparison of effect of mass transfer coefficient on $H / D$ ratio}

From the Figure 5, it seems that the addition of an external stirrer in the bubble column reactor increases the mass transfer coefficient values to a certain extent. This is due to the breaking of the gas bubbles which provides more contact area available for mass transfer between the phases. The external stirrer, which is responsible for agitation and creation of large interfacial area between the phases, increases the mass transfer coefficient.

\subsection{Comparison of effect of mass transfer coefficient on superficial gas velocity}

The variation of mass transfer coefficient for different superficial gas velocity was studied in 0.14 m i.d bubble column fitted with three Ruston turbine impeller having $0.046 \mathrm{~m}$ diameter. This effect is shown in Figure 6 for both with and without stirrer. From this figure, it can be seen that mass transfer coefficient increases as superficial gas velocity increases. The mass transfer coefficient is $20 \%$ more for stirred bubble column than compared to conventional bubble column. This may be due to additional effect of stirring which ensures uniform mixing in the vessel. Also, for stirred system, column is fully occupied by gas bubbles and more number of circulation loops is formed which makes stirred bubble column having high mass transfer coefficient.

\section{Conclusion}

- The mass transfer coefficient is more for stirred bubble column than conventional bubble column for the same scale up factors

- The mass transfer coefficient is found to decrease with increase in the H/D ratio.

- The mass transfer coefficient increases with an increase in impeller speed

- The mass transfer coefficient increases with increase in superficial gas velocity

References

Akita, K. and Yoshida, F. (1973). Gas hold-up and volumetric mass transfer coefficients in bubble columns. Ind. Eng. Chem. Process. Des. Dev., 12, 76-80. 
Ali Abdul R. N. Jasim (2009). Studies on gas hold-up, mass transfer coefficient, mixing time and circulation time in bubble columns with draught tube for pseudo plastic (carboxymethyl) cellulose and glycerol solutions. Eng. \& Tech. Journal, 27 (12), 2245-2256.

Alvarez-cunca, M. and Nerenbreg, M. A. (1980). Oxygen mass transfer in bubble columns working at an liquid flow rates. AICHE, J., 27, 66.

Burekhart, R. and Deckwer, W. D. (1976). Bubble size distribution and interfacial areas of electrolyte solutions in bubble columns. Chem. Eng. Sci., 30, 35.

Deckwer, W. D., Burckhart, R. and Zoll, G. (1974). Mixing and mass transfer in tall bubble columns. Chem. Eng. Sci., 29, 2177-2188.

Haque, M. N., Nigam, K. D. P., Joshi, J. B. and Viswanathan, K. (1987). Studies on mixing time in bubble columns with pseudo plastic (carboxymethyl cellulose) solution. Ind. Eng., 26, 82-86.

Hikita, H., Asal, S., Kikukawa, H., Zalke, T. and Ohue, M. (1981). Heat transfer coefficient in bubble column. Ind. Eng. Chem. Process Des. Dev., 20, 540-545.

Kang, Y., Cho, Y. J., Woo, K. J. and Kim, S. D. (1999). Diagnosis of bubble distribution and mass transfer in pressurized bubble columns with viscous liquid Medium. Chem. Eng. Sci., 54, 4887.

Kawase, Y. and Moo-Young, M. (1987). Heat transfer in bubble column reactors with Newtonian and non-Newtonian fluids. Chem. Eng. Res. Des., 65, 121-126.

Koide, K., Takazawa, A., Komura, M. and Matsunage, H. (1984). Gas hold-up of volumetric liquid phase mass transfer in solid suspended bubble columns. J. Chem. Eng. Japan, 17 (5), 459- 466.

Lye and Stuckey (2001). Extraction of Erthromycin- a using colloidal liquid aphrons: part 2. Mass Transfer Kinetics, Chemical Engineering Science, 56, 97-108.

Maclean, G. F., Erickson, L. E., Hsu, K. H. and Fan, L. T. (1977). Oxygen transfer and axial dispersion in an aeration tower containing Static mixers. Biotechn. Bioengng., 19, 493.

Mangertz K.H. and Pilhofer (1981). Interpretation of mass transfer measurements in bubble columns considering dispersion of both phases. Chem. Eng. Sci., 36, 1069.

Mashelkar, R. A. and Sharma, M. M. (1970). Mass transfer in bubble columns. Trans. Inst. Chem. Eng., 48, T162.

Ozturk, S. S., Schumpe, A. and Deckwer, W. D. (1987). Organic liquids in a bubble column: holdups and mass transfer coefficients. AIChE, J., 33, 1473-1480.

Pandit, A. B. and Joshi, J. B. (1984). Three phase sparged reactions, some design aspects. Rev. Chem. Eng., 2, $1-84$.

Schugerl, K., Lucke, J. and Oels, U. (1977). Bubble column bioreactions. Adv. Biochem. Eng., 7, 1.

Schumpe, A. and Grund, G. (1986). The gas disengagement technique for studying gas holdup structure in bubble columns. Can. J. Chem. Eng., 64, 891-896.

Shah, Y. T., Kelkar, B.G., Godbole, S. P. and Deckwer, W. D. (1982). Design parameters estimations for bubble column reactors. AIChE, J., 28 (3), 353-379.

Shanmugam, K., Saravanan, K., Ramamoorthy, V. \& Balasubramani, R. (2008). Hydrodynamic studies in stirred bubble column. Journal of the University of Chemical Technology and Metallurgy, 43 (1), 113-118.

Shiaya, S. and Duna, I. J. (1978). Dynamic oxygen mass transfer coefficient measurement method for column reactors. Chem. Eng. Sci., 33, 1529.

Thorat, B. N and Joshi, J. B. (2004). Regime transition in bubble columns: experimental and predictions. Exp. Therm. Fluid Sci., 28, 423-30.

Urza, I. J. and Jackson (1975). Pressure aeration in a 55-ft bubble column. Ind. Eng. Chem. Process Des. Dev., 14, 106.

Yang, W., Wang, J. and Jin, Y. (2001). Gas-Liquid Mass Transfer in a slurry Bubble Column Reactor under High Temperature and High Pressure. Chinese Journal of Chemical Engineering, 9 (3), 253-257. 
Table 1. Details for Sparger design

\begin{tabular}{|l|l|}
\hline Total area of sparger & $0.0154 \mathrm{~m}^{2}$ \\
\hline Active area of sparger & $0.0158 \mathrm{~m}^{2}$ \\
\hline Free area of sparger & $0.0138 \mathrm{~m}^{2}$ \\
\hline Effective area of sparger & $67 \%$ \\
\hline Diameter of hole for square and triangular pitch & $6.7 \times 10^{-3} \mathrm{~m}$ \\
\hline Diameter of hole for single orifice & $4.5 \times 10^{-3} \mathrm{~m}$ \\
\hline $\begin{array}{l}\text { Number of holes in distributor for square and } \\
\text { triangular pitch }\end{array}$ & 45 \\
\hline Material & Mild steel \\
\hline Sparger vessel thickness & $0.003 \mathrm{~m}$ \\
\hline
\end{tabular}

Table 2. Details for column design

\begin{tabular}{|l|l|}
\hline Column diameter & $0.14 \mathrm{~m}$ \\
\hline Column length & $2 \mathrm{~m}$ \\
\hline Material of column & Acrylic \\
\hline Number of impellers & 3 \\
\hline Type of impeller & Rushton Impeller \\
\hline Gap between the impeller & $0.046 \mathrm{~m}$ \\
\hline Clearance of impeller from vessel bottom & $0.046 \mathrm{~m}$ \\
\hline
\end{tabular}

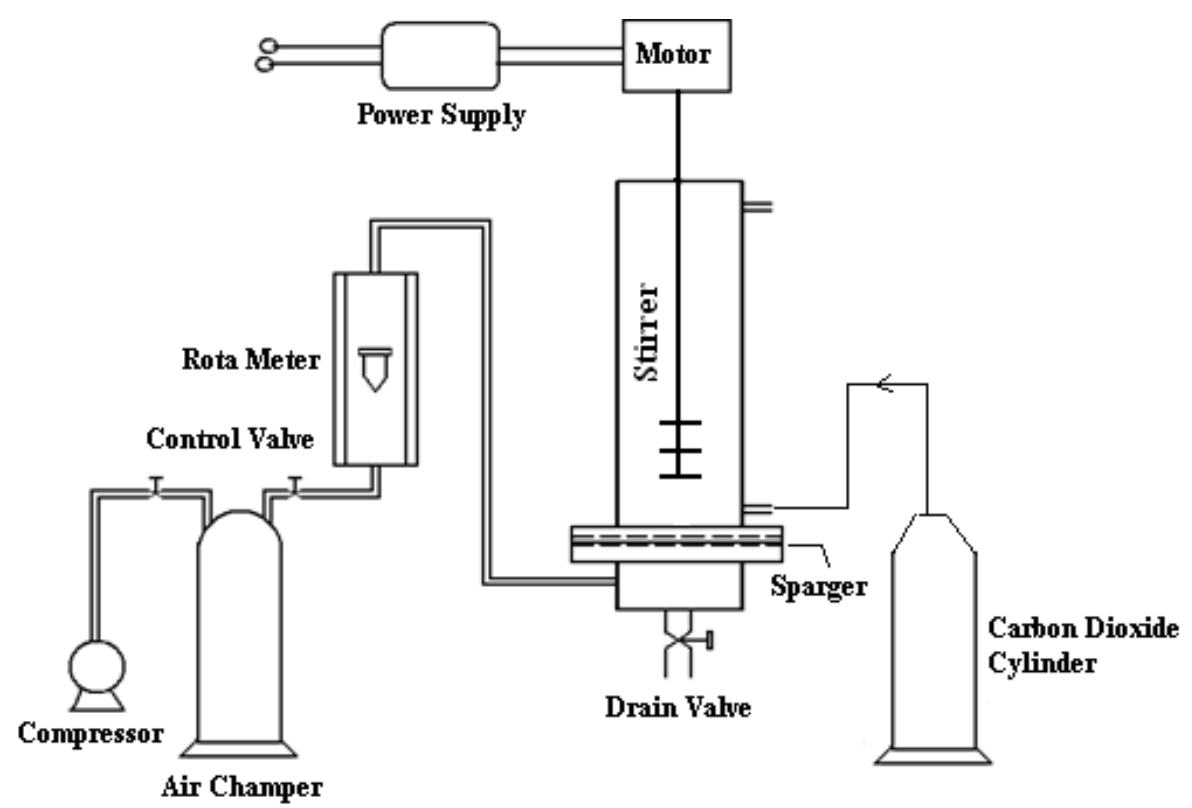

Figure 1. Experimental setup for stirred bubble column reactor 


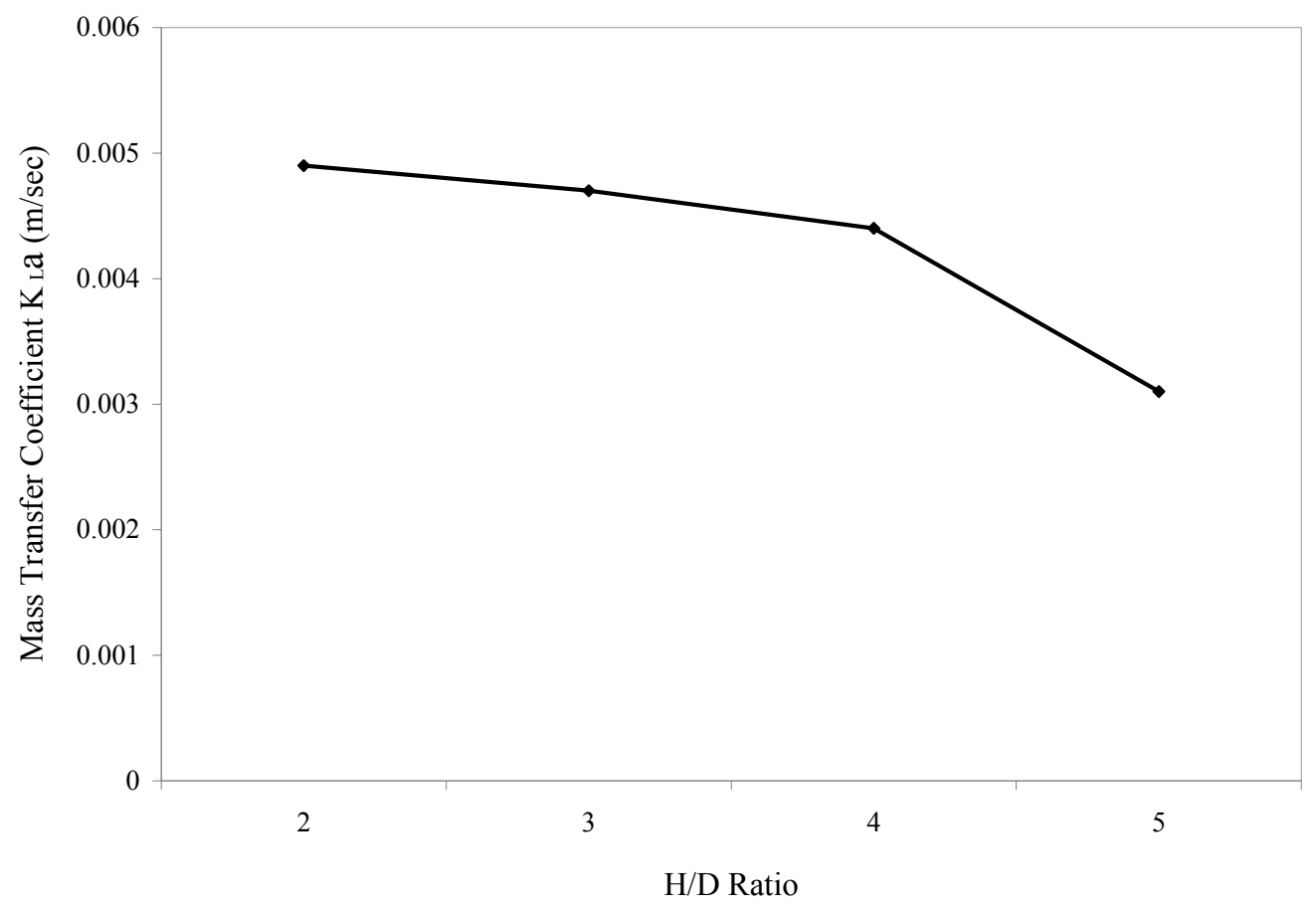

Figure 2. Effect of mass transfer coefficient on $\mathrm{H} / \mathrm{D}$ ratio (Air flow rate $=0.42 \mathrm{lpm}$, Speed of the stirrer $=100 \mathrm{rpm}$ )

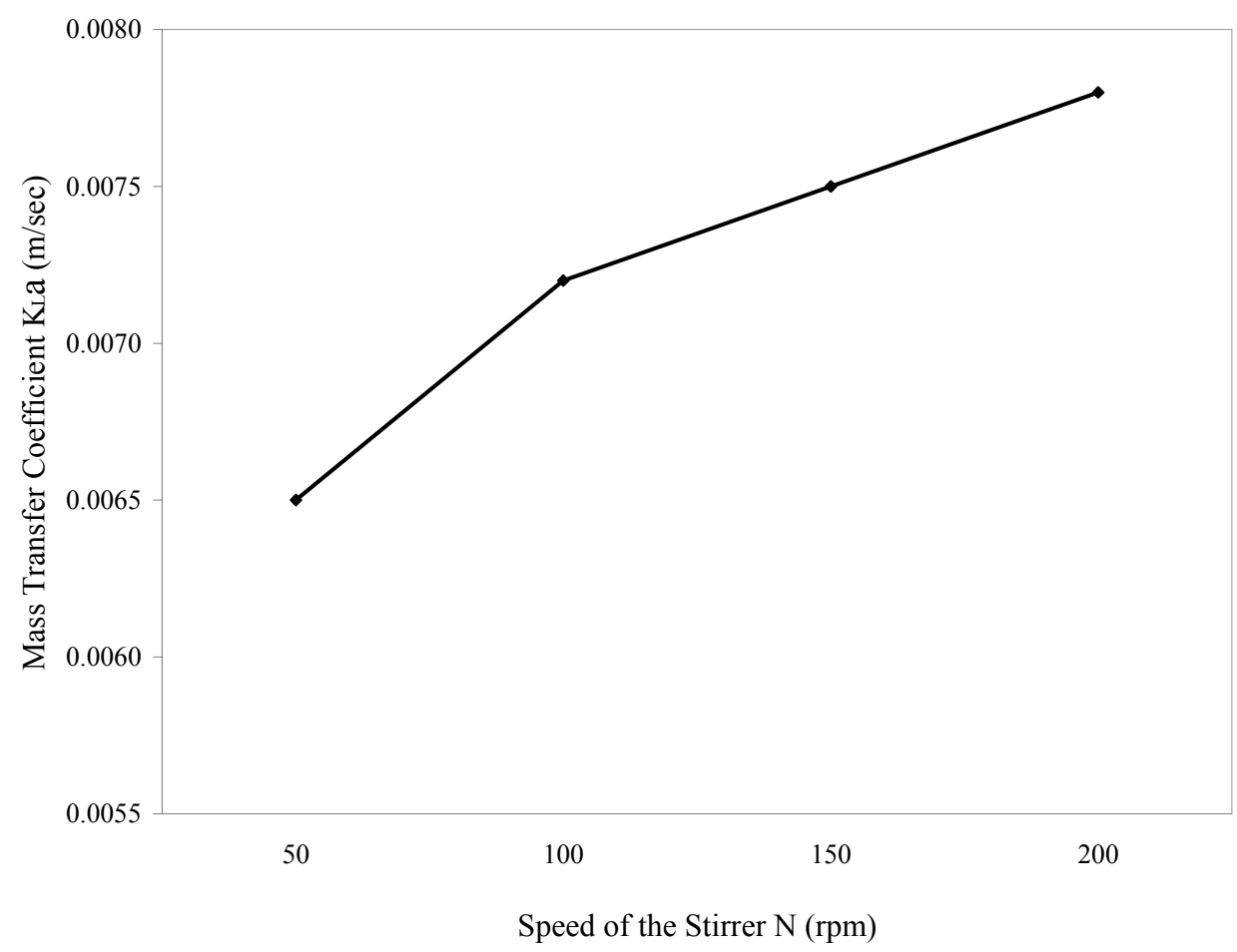

Figure 3. Effect of mass transfer coefficient on speed of the stirrer $(\mathrm{H} / \mathrm{D}$ ratio $=4$, Air flow rate $=0.42 \mathrm{lpm})$ 


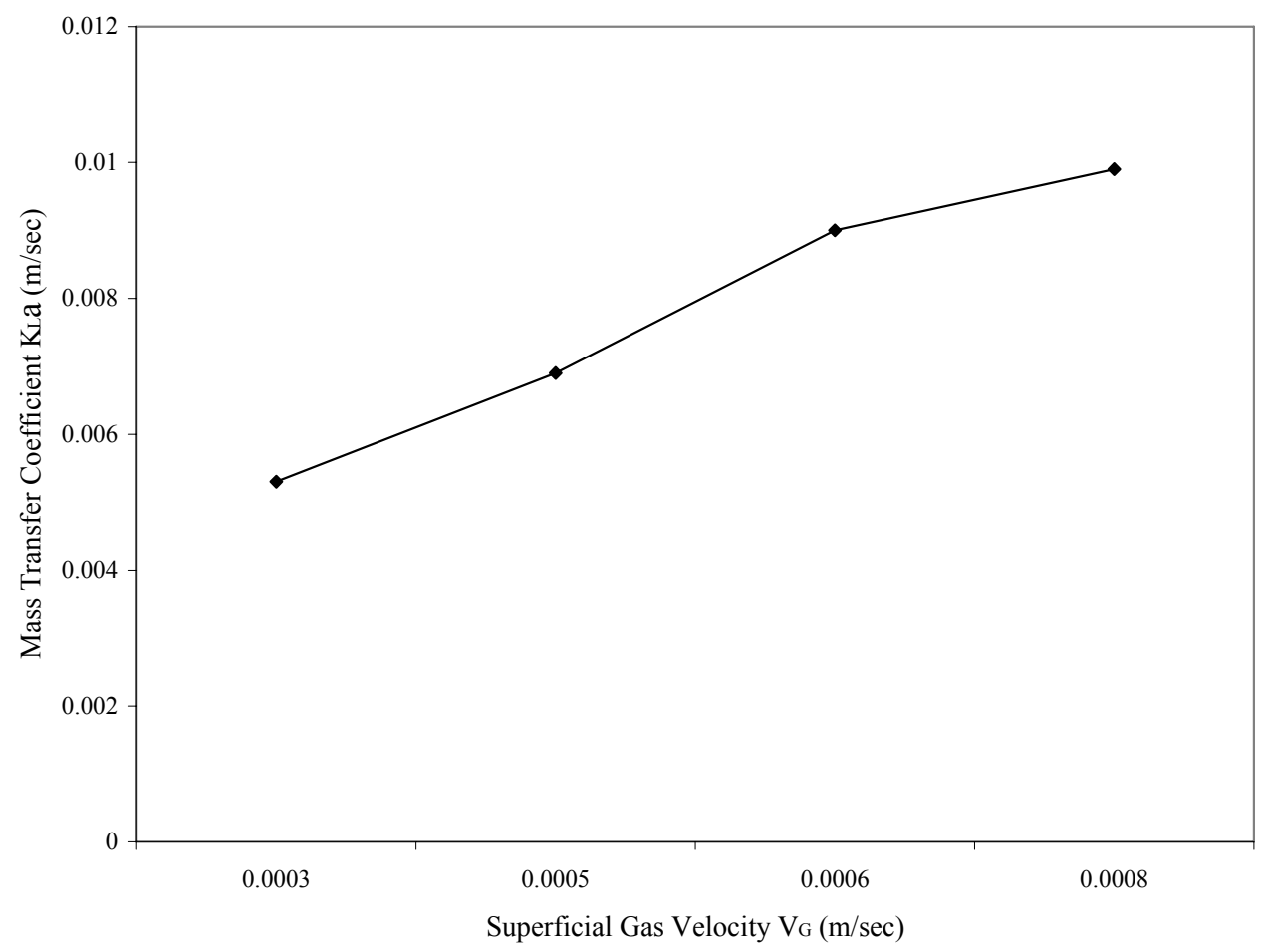

Figure 4. Effect of Mass transfer coefficient on superficial gas velocity $(\mathrm{H} / \mathrm{D}$ ratio $=4$, Speed of the stirrer $=100 \mathrm{rpm})$

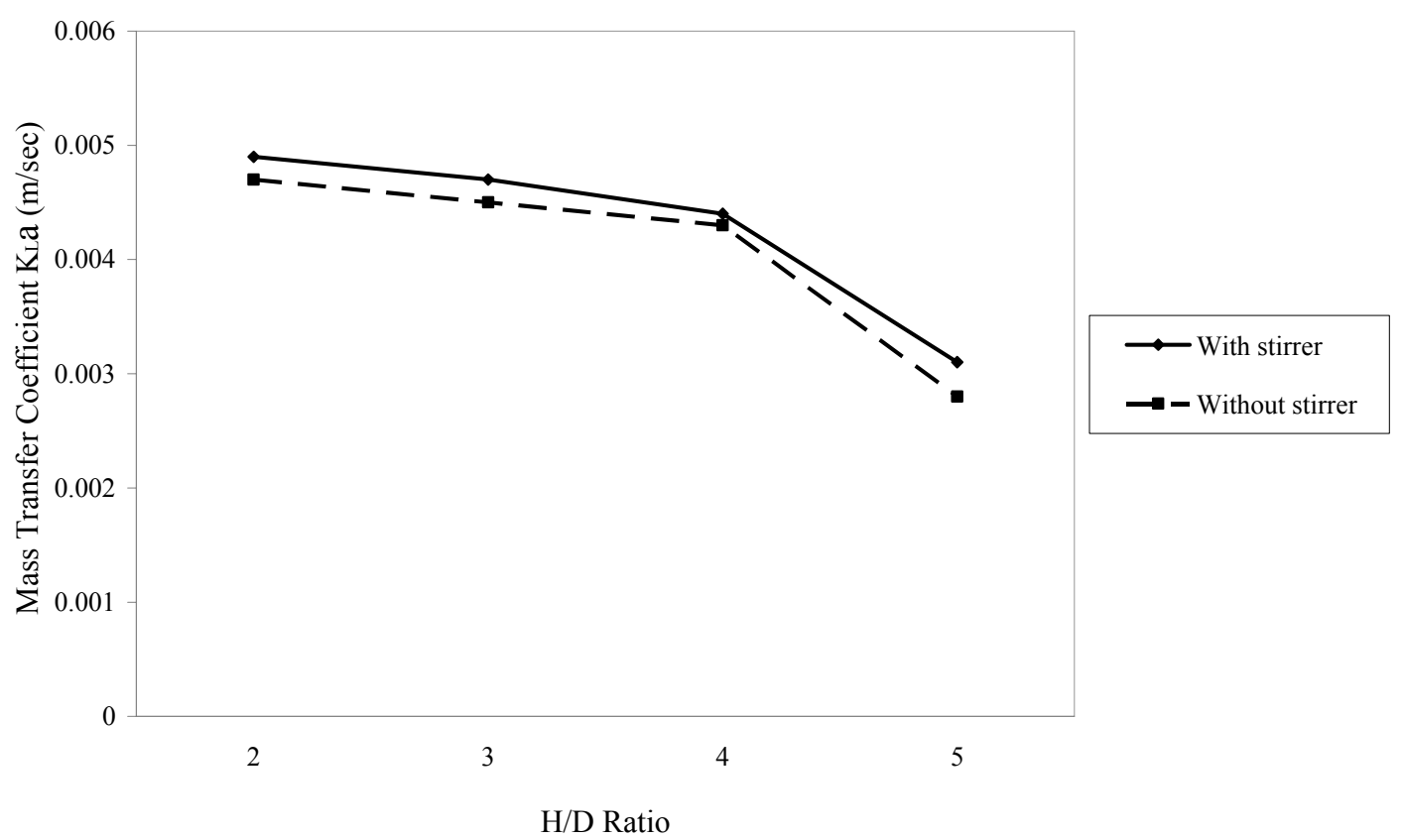

Figure 5. Comparison of effect of mass transfer coefficient on H/D ratio (Speed of the stirrer $=100 \mathrm{rpm}$, Air flow rate $=0.42 \mathrm{lpm})$ 


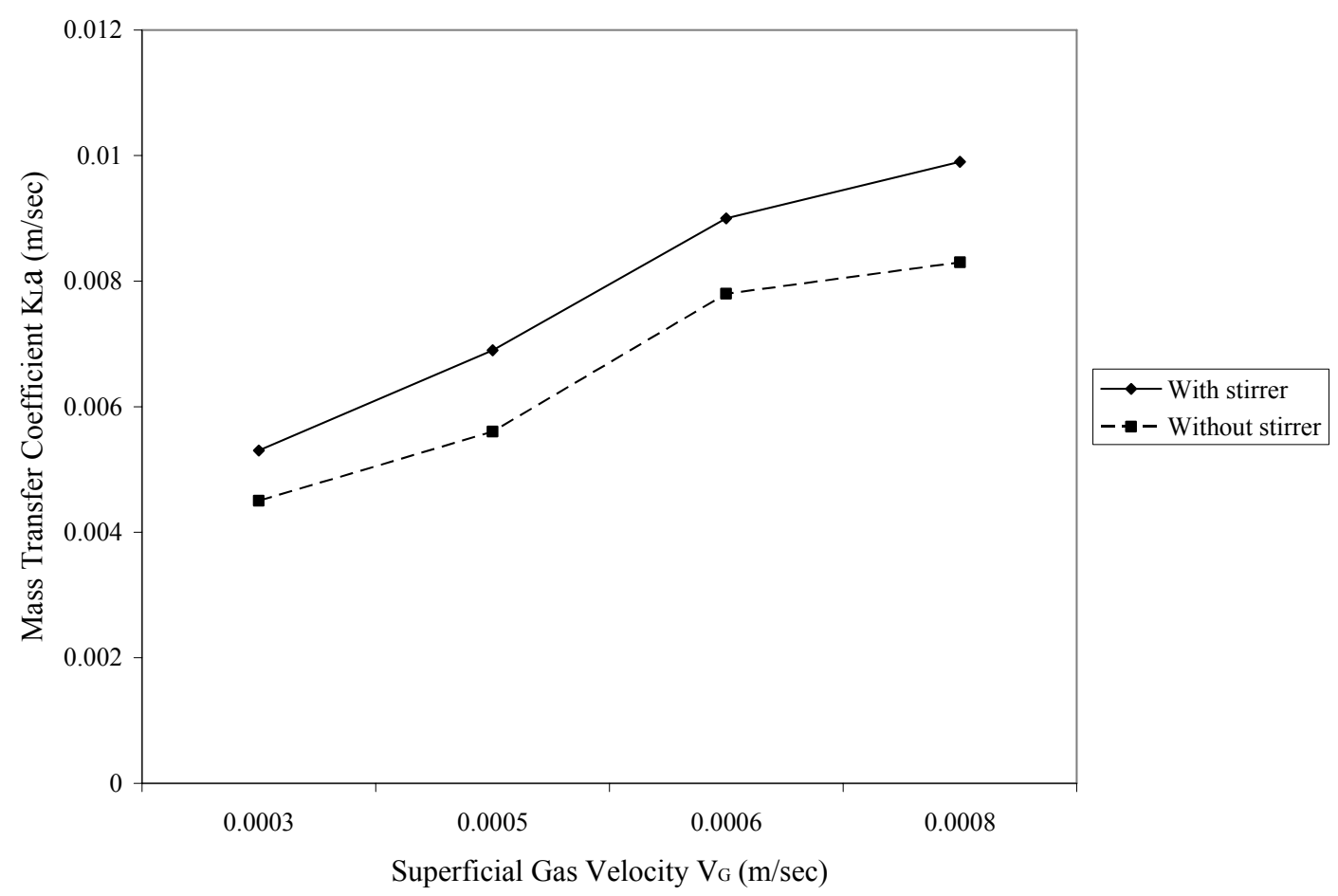

Figure 6. Comparison of effect of mass transfer coefficient on superficial gas velocity $(\mathrm{H} / \mathrm{D}$ ratio $=4$, Speed of the stirrer $=100 \mathrm{rpm})$ 